\title{
Um olhar sobre a evasão de estudantes universitários durante os estudos remotos provocados pela pandemia do COVID-19
}

\author{
An overview of the evasion of university students during remote studies caused by COVID-19
}

pandemic

Una mirada a la evasión de estudiantes universitarios durante estudios remotos provocada por la pandemia COVID-19

Recebido: 16/02/2021 | Revisado: 21/02/2021 |Aceito: 24/02/2021 | Publicado: 03/03/2021

\author{
Renata Cristina Nunes \\ ORCID: https://orcid.org/0000- 0001-8451-6845 \\ Instituto Federal de Educação, Ciência e Tecnologia Fluminense, Brasil \\ E-mail: renatacn@iff.edu.br
}

\begin{abstract}
Resumo
O objetivo desse trabalho foi analisar de que forma os estudantes universitários estão lidando com o ensino remoto e quais fatores estão relacionados à sua decisão de abandonar disciplinas. A metodologia foi descritiva com abordagem qualitativa. Os meios de investigação utilizados caracterizam este estudo como Levantamento. Os estudantes que participaram da pesquisa são de cursos superiores do Instituto Federal de Educação, Ciência e Tecnologia Fluminense - campus Cabo Frio que, por conta do fechamento das escolas causado pela pandemia do COVID-19, começou a oferta do ensino remoto a partir de setembro de 2020. Os resultados indicam que os estudantes estão cansados, ansiosos, estressados, desanimados, desmotivados e aprendendo menos. Muitos estudantes relacionam a falta de tempo como razão para a desistência, por trás dessa resposta revelam-se a sobrecarga de trabalho, as tarefas domésticas mas esconde-se a falta de uma rotina de estudos. O momento é desafiador para as instituições, mas o desafio não se encerra com o retorno às atividades presenciais. Será necessário tomar medidas para lidar com os sentimentos desses estudantes e também com as deficiências de aprendizado que possam ter ocorrido.
\end{abstract}

Palavras-chave: COVID-19; Evasão; Ensino superior; Ensino.

\begin{abstract}
This work aimed to analyze how university students are dealing with remote education and what factors are related to their decision to abandon subjects. The methodology for doing so was descriptive with a quantitative approach. The means of investigation used characterize this study as a survey. The students who took part in the research are from higher education courses at the Federal Institute of Education, Science and Technology Fluminense - Cabo Frio campus, which, with the closure of schools caused by the pandemic of COVID-19, has been offering remote education since September 2020. The results showed that students are tired, anxious, stressed, discouraged, demotivated and learning less. Many students say that the lack of time is a reason for dropping out, behind this answer are, in fact, overwork, housework, but the lack of a study routine is hidden in that way. The moment is challenging for institutions, but the challenge does not end with the return to face-to-face activities. It will be necessary to take more steps to deal with the feelings of those students and also with any learning achievement problem that may have happened.
\end{abstract}

Keywords: COVID-19; Dropout students; Higher education; Teaching.

\section{Resumen}

El objetivo de este trabajo fue analizar cómo los estudiantes universitarios están lidiando con la educación a distancia y qué factores están relacionados con su decisión de abandonar las asignaturas. La metodología fue descriptiva con enfoque cualitativo. Los medios de investigación utilizados caracterizan este estudio como Encuesta. Los estudiantes que participaron en la investigación son de cursos de educación superior del Instituto Federal de Educación, Ciencia y Tecnología Fluminense - campus Cabo Frio, que debido al cierre de escuelas provocado por la pandemia de COVID19, comenzó a ofrecer educación a distancia desde Septiembre de 2020. Los resultados indican que los estudiantes están cansados, ansiosos, estresados, desanimados, desmotivados y aprendiendo menos. Muchos alumnos relacionan la falta de tiempo como motivo de deserción, detrás de esta respuesta se encuentran el exceso de trabajo, las tareas del hogar, pero se esconde la falta de una rutina de estudio. El momento es un desafío para las instituciones, pero el desafío no termina con el regreso a las actividades presenciales. Será necesario tomar medidas para lidiar con los sentimientos de estos estudiantes y también con las discapacidades de aprendizaje que puedan haber ocurrido. 
Palabras clave: COVID-19; Evasión; Enseñanza superior; Enseñanza.

\section{Introdução}

O ano de 2020 será sempre lembrado devido ao início de uma crise mundial sem precedentes, a pandemia causada pelo COVID-19 que, apesar dos avanços científicos e tecnológicos, não encontrou uma solução rápida a não ser orientar o isolamento social como medida preventiva.

Em nenhum outro momento da história, a educação precisou passar por mudanças de forma tão rápida quanto às que ocorreram nesse cenário. Dados da UNESCO revelam que no auge da crise 1,6 bilhão de estudantes foram afetados por essa situação, a instituição chama de "a maior interrupção da aprendizagem da história" (UNESCO, 2020). No Brasil, a Portaria n 343, de 17 de março de 2020 (alterada pela Portarias n 345/2020) autorizou a substituição das aulas presenciais por aulas em meios digitais enquanto durar a situação da pandemia (exceto estágios, práticas de laboratório e, para o curso de Medicina, residência).

As instituições de ensino, públicas e privadas, precisaram se adaptar rapidamente para garantir a manutenção da oferta da educação de forma segura. Diretrizes tiveram que ser discutidas para orientar o trabalho nesse novo período e novos Planos Pedagógicos de Curso tiveram que ser elaborados. Essa oferta alternativa de ensino esbarrou em uma série de problemas, principalmente no setor público, que costuma ter uma velocidade de mudanças mais lenta, quando comparado ao setor privado. Segundo Gusso et al, dentre esses problemas encontram-se

a) falta de suporte psicológico a professores; b) a baixa qualidade no ensino (resultante da falta de planejamento de atividades em "meios digitais"); c) a sobrecarga de trabalho atribuído aos professores; d) o descontentamento dos estudantes; e e) o acesso limitado (ou inexistente) dos estudantes às tecnologias necessárias. (Gusso et al, 2020, p.4)

Barbosa et al (2020) observaram em pesquisa junto a professores universitários que $79 \%$ dos docentes não receberam nenhum suporte financeiro das instituições em que atuam para adquirir o equipamento necessário para a oferta das aulas remotas. Carneiro et al (2020) ainda colocam como um dos grandes desafios o acesso à internet, que apesar de estar presente em 67\% dos domicílios brasileiros muitas vezes não é de alta velocidade. Dados da pesquisa TIC Domicílios 2019 mostrou que $92 \%$ da classe média está conectada, no entanto apenas $48 \%$ da população de baixa renda têm algum tipo de acesso à Internet, quase sempre via celular. (Núcleo da Informação e Coordenação do Ponto BR, 2019). Couto et al (2020) alertam que com essa conexão lenta e instável, muitos estudantes sequer conseguem estudar, ampliando a desigualdade educacional entre as classes sociais.

Grande parte dessas instituições já possuía experiência na oferta de Educação a Distância (EaD) que de acordo com o Decreto $\mathrm{n}^{\circ} 9057$ de 25 de maio de 2017

(...) considera-se educação a distância a modalidade educacional na qual a mediação didático pedagógica nos processos de ensino e aprendizagem ocorra com a utilização de meios e tecnologias de informação e comunicação, com pessoal qualificado, com políticas de acesso, com acompanhamento e avaliação compatíveis, entre outros, e desenvolva atividades educativas por estudantes e profissionais da educação que estejam em lugares e tempos diversos. (Decreto $\mathrm{n}^{\circ} 9057$ de 25 de maio de 2017, 2017, p.1)

Entretanto, é preciso deixar claro que a oferta emergencial da educação no período da pandemia utilizando meios tecnológicos não pode ser caracterizada como Educação a Distância. Enquanto essa última é uma oferta planejada técnica e pedagogicamente, na qual ocorre capacitação do pessoal envolvido e os estudantes fazem opção por essa modalidade, na primeira não houve tempo hábil para um planejamento efetivo. Aspectos pedagógicos e tecnológicos da realidade de estudantes e professores podem ter sido negligenciados. A despeito de terem pessoal qualificado para auxiliar os docentes que tinham interesse no desenvolvimento de atividades online ou mesmo na oferta de cursos a distância antes da pandemia, o 
número de disciplinas, docentes e estudantes a serem assistidos nesse período aumentou enormemente. Hodges et al (2020) são categóricos ao afirmar que é impossível terem o mesmo suporte de qualidade que era oferecido anteriormente, assim como viabilizar condições mínimas para o desenvolvimento e implementação de cursos de qualidade. Eles ainda advertem que essa redução na qualidade que ocorre pode aumentar o estigma que a $\mathrm{EaD}$ tem de ser um curso inferior ao presencial. Barbosa et al (2020) questionaram os professores atuando de forma remota a respeito da experiência que tinham anteriormente com essa forma de aula e apenas 58,1\% responderam positivamente. A pesquisa aponta ainda que $67,7 \%$ das instituições ofereceram algum tipo de capacitação para os docentes atuarem nesse momento excepcional.

Apesar de toda a adaptação que as instituições fizeram com o objetivo de manter a oferta da educação, houve um aumento nos níveis de ansiedade, depressão e estresse entre os estudantes. Baseado em resultados de outras pesquisas, não é exagero afirmar que isso pode levar à diminuição da motivação aumentada pela pressão de estudar de forma independente e a interrupção da rotina diária. A consequiência será um aumento potencial nas taxas de evasão. (Grubic et al, 2020, Meeter et al, 2020), visto que a motivação é um dos fatores determinantes na decisão de evadir (Chyung, 2001, Levy, 2007, Tinto 1998)

No modelo proposto por Tinto (Tinto, 1998), um dos pesquisadores mais influentes nos estudos sobre evasão, ao lado da motivação, a integração social e acadêmica dos estudantes tem um enorme peso na evasão. Uma das limitações do modelo de Tinto é que ele foi elaborado para estudantes tradicionais, enquanto que os estudantes de $\mathrm{EaD}$ (e os de ensino remoto estão mais próximos desses do que dos tradicionais) são considerados estudantes não-tradicionais. A principal diferença apontada em trabalhos posteriores (Kember, 1989) é que estudantes de cursos a distância são mais afetados por fatores externos à instituição. Tem-se ainda que estudantes que interagem melhor com seus pares e com outros funcionários da instituição relatam maiores níveis de satisfação e motivação. (Trolian et al, 2016). No momento em que as interações sociais são dificultadas por conta da recomendação do isolamento, o quadro é bastante preocupante visto que ainda é necessária uma integração tecnológica rápida por parte dos estudantes.

Fritsch et al (2015) recordam que as causas podem ser internas ou externas à instituição. Para Rumberger (2004) como citado em Dore e Lüscher (2011), um dos mais importantes pesquisadores dessa questão nos Estados Unidos, "entender as causas da evasão é a chave para encontrar soluções para o problema". O fenômeno é bastante complexo e dinâmico e precisa ser estudado durante essa oferta emergencial. Estudos anteriores (Park \& Choi, 2009) utilizaram três principais categorias que podem levar um estudante a interromper seu curso antes de concluí-lo: características do estudante, fatores externos e fatores internos. Como características dos estudantes destacam-se idade, gênero, histórico educacional e situação empregatícia.

No Brasil, os dados revelam que é alto o número de estudantes que vêm abandonado as universidades. Um levantamento feito pelo Datafolha a pedido do C6 Bank indica que 8,4\% dos estudantes com idade entre 6 e 34 anos abandonaram a escola durante a pandemia, esses números correspondem a cerca de 4 milhões de estudantes. A taxa de abandono foi de 10,8\% no ensino médio e 16,3\% no ensino superior. A pesquisa foi realizada entre os dias 30 de novembro e 9 de dezembro de 2020. As principais razões apontadas pelos universitários foram falta de dinheiro para pagar as mensalidades, no caso das instituições privadas, e precariedade na oferta do ensino remoto, no caso das instituições públicas (Saldaña, 2021).

O objetivo desse trabalho foi compreender como os estudantes estão lidando com o ensino remoto e de que forma o contexto como estão inseridos está influenciando na decisão de abandonar disciplinas durante esse período.

\section{Metodologia}

No que tange à metodologia, essa pesquisa foi descritiva com relação aos seus objetivos. Conforme apresentado por Gil, "As pesquisas descritivas têm como objetivo primordial a descrição das características de determinada população ou 
fenômeno ou, então, o estabelecimento de relações entre variáveis. (Gil, 2020, p. 42).

A abordagem utilizada foi a quantitativa, visto que segundo Pereira et al (2018) muitas vezes os métodos qualitativos transformam-se em quantitativos pela utilização de questões fechadas e escala de Likert. Entretanto, não foram feitas análises estatísticas dos dados obtidos. Os meios de investigação utilizados foram interrogação direta dos estudantes cujas opiniões e comportamento desejava-se conhecer o que permite caracterizá-la como Levantamento (Survey) (Gil, 2002).

Neste trabalho, o interesse foi voltado para estudantes dos cursos superiores de Licenciatura em Química, Licenciatura em Física, Licenciatura em Biologia, Engenharia Mecânica, Tecnólogo em Gastronomia e Tecnólogo em Hotelaria do campus Cabo Frio do Instituto Federal de Educação, Ciência e Tecnologia Fluminense.

$\mathrm{O}$ instrumento de coleta de dados foi elaborado a partir dos Formulários Google disponíveis no Google Drive. O questionário contava com oito seções sendo que algumas eram dependentes de respostas anteriores: a $1^{\text {a }}$ seção abordava questões sobre o curso; a $2^{\mathrm{a}}$ seção continha questões sobre atividades extras desenvolvidas; na $3^{\mathrm{a}}$ seção abordavam-se as condições de estudo para aqueles estudantes que selecionaram a opção de estar trabalhando na seção anterior; a $4^{\mathrm{a}}$ seção investigava características gerais dos respondentes; a $5^{\text {a }}$ seção procurou saber as condições de estudo durante o desenvolvimento das atividades remotas. $\mathrm{Na} 6^{\mathrm{a}}$ seção o estudante deveria assinalar se havia evadido de alguma disciplina. Se a resposta fosse não, o questionário era encerrado. Se a resposta fosse positiva, ele era redirecionado à $7^{\mathrm{a}}$ seção (caso tivesse evadido de todas) ou à $8^{a}$ seção (caso tivesse evadido de algumas disciplinas). O link com o questionário foi enviado através dos grupos de Whatsapp e essa divulgação contou com a colaboração dos coordenadores e professores dos referidos cursos. As respostas foram recebidas entre os dias 26 de novembro e 30 de dezembro de 2020.

O método de amostragem foi a Amostragem Aleatória Simples (AAS), ou seja, todos os indivíduos da população possuem a mesma chance de participar da amostra o que garante o princípio da eqüiprobabilidade (Paranhos et al, 2013). Através de informações fornecidas por servidoras do Registro Acadêmico da instituição, levantou-se que na ocasião da pesquisa havia 464 estudantes matriculados nos cursos de ensino superior, sendo que 106 responderam ao questionário. Esses dados acarretam em um erro amostral de $7 \%$ quando se define um grau de confiança de $90 \%$.

\section{Resultados e Discussão}

As respostas reveladas nos questionários são apresentadas abaixo e quando são fatores que são descritos na literatura como sendo relacionados à evasão de estudantes são feitas correlações entre eles e a evasão de disciplinas. Conforme sinalizam Fritsch et al (2015) "O conceito de evasão depende da granularidade e da temporalidade da informação a ser pesquisada. Dessa forma, a evasão pode ser mensurada a partir da disciplina, do curso, da instituição ou do sistema educacional.” Sendo assim, será considerado que houve evasão se o estudante tiver abandonado uma ou mais disciplinas, ou mesmo todas.

No Instituto Federal de Educação, Ciência e Tecnologia Fluminense (IFFluminense) os calendários letivos foram suspensos no dia 16 de março de 2020 e foram reabertos no dia 31 de agosto de 2020 por meio da Portaria $\mathrm{n}^{\circ} 577$ que permitiu a realização de Atividades Pedagógicas Não Presenciais (APNPs) nos campi do IFF, adaptadas a cada curso/turma. No campus Cabo Frio as atividades foram autorizadas através da Ordem de Serviço n 33 de 22 de setembro de 2021. O semestre letivo foi dividido em quatro ciclos de cinco semanas cada e cada docente teve liberdade para definir quantos ciclos utilizaria para seu componente curricular. O primeiro ciclo teve início no dia 21 de setembro de 2020 e o quarto ciclo será encerrado no dia 12 de março de 2021. As atividades foram realizadas utilizando o ambiente virtual Modular Object-Oriented Dynamic Learning Environment (MOODLE) e também ferramentas de webconferência como o Google Meet e o Comunidade Acadêmica Federada (CAFE) da RNP. Antes do início das disciplinas, foi dado um treinamento aos estudantes de como utilizar o MOODLE. 


\subsection{Sobre o curso}

Com relação ao curso, os respondentes dividem-se da seguinte forma: 24,5\% estão cursando Licenciatura em Biologia; 21,5\% Tecnólogo em Gastronomia; 18,9\% Licenciatura em Química; 17\% Tecnólogo em Hotelaria; 10,4\% Licenciatura em Física e 7,5\% Engenharia Mecânica. o total de respondentes, 26,4\% ingressaram no curso em 2020, ou seja, a experiência com o ensino presencial foi de poucas semanas antes da suspensão das aulas. A maioria dos estudantes (60,4\%) estava cursando mais de cinco disciplinas de forma remota, enquanto os demais estavam cursando uma disciplina (1,9\%), duas $(1,9 \%)$, três $(11,3 \%)$, quatro $(7,5 \%)$ e cinco (17\%). Esses estudantes permaneceram cerca de seis meses sem contato com a instituição e esse resultado demonstra uma vontade de ficar regular com o curso e recuperar o tempo perdido. Dentre esses estudantes, apenas 13,2\% não estavam regulares no curso no início de 2020, ou seja, haviam sido reprovados ou abandonado disciplinas em outros períodos. De forma surpreendente, quando é correlacionada a taxa de evasão das disciplinas com o número de disciplinas que o estudante está matriculado, a menor evasão $(18,7 \%)$ ocorreu entre aqueles estudantes que estavam matriculados em mais de cinco componentes curriculares. A surpresa é originada pelo fato de que muitos estudantes, conforme será apresentado, apontam a falta de tempo como razão para o abandono e estudantes que estão em um maior número de disciplinas poderiam estar com uma maior sobrecarga.

\subsection{Atividades extras desenvolvidas}

Esta etapa é importante para a compreensão das demandas enfrentada pelos estudantes ao dedicarem-se a outras atividades como outros cursos, tarefas domésticas e trabalho. Quando questionados a respeito da realização de outros cursos, além do curso superior, 47,2\% assinalaram não ter outras atividades, 39,6\% estão fazendo cursos de natureza diversas (cursos de língua, curta duração, entre outros), 11,3\% estão em um curso técnico e 7,5\% cursam simultaneamente outro curso superior.

Quando se trata da participação na realização de tarefas domésticas, 31,1\% fazem todas as tarefas em casa, 21,7\% fazem a maior parte, $33,0 \%$ dividem igualmente com outras pessoas, $12,3 \%$ fazem poucas tarefas e apenas $1,9 \%$ não tem nenhuma participação. Quando é aplicado o filtro de gênero e somam-se aqueles indivíduos que fazem todas as tarefas com os que fazem a maior parte, nota-se que $60 \%$ das mulheres encontram-se nessa situação enquanto que entre os homens esse percentual é de 41,6\%. Essa desigualdade na distribuição das tarefas domésticas é histórica, não possuindo qualquer relação com a pandemia. No entanto, é bastante provável que tenha havido um aumento dessas tarefas visto que os filhos encontram-se em casa em tempo integral (Lemos et al, 2020). Dados divulgados pelo Instituto Brasileiro de Geografia e Estatística (IBGE) trazem à tona essa discrepância, enquanto 92,2\% das mulheres realizam algum tipo de trabalhos domésticos entre os homens cai para 78,2\% (IBGE, 2019).

Arntz et al (2020) observaram que, ao contrário de outras crises econômicas nas quais os homens foram mais afetados (Alon et al, 2020), nessa as mulheres tem sido mais impactadas por conta do fechamento de serviços como creches e escolas e a desigualdade que ainda ocorre na distribuição das tarefas domésticas e de cuidado com os filhos. Apesar dos autores terem analisado as condições de homeoffice, tal análise também pode ser aplicada para o ensino remoto como averiguado por Bartmeyer e Salles Filho (2020), que demonstraram que as estudantes de graduação e pós-graduação da Universidade Estadual de Ponta Grossa encontram-se com maior sobrecarga que os estudantes.

No que se refere à situação envolvendo trabalho, 48,1\% não estão trabalhando e nem estavam antes da pandemia. $19,8 \%$ estão no mesmo trabalho que se encontravam antes da pandemia, 14,2\% começaram a trabalhar durante a pandemia, 9,4\% mudaram de trabalho e 8,5\% foram demitidos durante a pandemia. Esses dados têm impacto direto na evasão de disciplinas, conforme será apresentado. 


\subsection{Condições de estudo no trabalho}

Apenas aqueles que respondiam que estavam trabalhando tinham acesso a essas perguntas, ou seja, 43,4\% dos estudantes. Desses, $37,5 \%$ permanecem mais do que 40 horas semanais no trabalho enquanto 22,9\% têm jornada semanal entre 30 e 40 horas. Esse resultado indica o quanto pode ser complicado para esses estudantes adequarem-se à rotina de estudos remotos que exige tanta organização, tempo e autonomia. A situação é ainda mais crítica quando são perguntados se tem liberdade para assistir às aulas no ambiente de trabalho, visto que 66,7\% não têm. Esse resultado demanda atenção da instituição e dos docentes para evitar encontros síncronos que não sejam gravados e prejudicar esse grupo que não possui flexibilidade de horário.

\subsection{Características dos estudantes}

No que se refere às características dos estudantes que participaram da pesquisa, a maior parte é formada por mulheres $(61,3 \%)$ e mostrou-se um público jovem $(65,1 \%$ têm menos de 24 anos). Com relação às outras faixas etárias, observou-se que $15,1 \%$ possuem entre 25 e 34 anos, $11,3 \%$ entre 35 e 44 anos e 8,5\% entre 45 e 60 anos. Um público mais jovem pode estar mais familiarizado com as Tecnologias da Informação e Comunicação (TIC) tão necessárias nesse momento.

Sobre o grau de escolaridade do pai e da mãe, os resultados são mostrados na Tabela 1. Observa-se que a evasão é alta entre os estudantes que possuem pais e mãe menos escolarizados.

A escolaridade dos pais e das mães parece possuir uma estreita relação com a tendência que um indivíduo tem a evadir. Observa-se em estudos anteriores (Silva et al, 2016) que a maior escolaridade, principalmente da mãe, ocasiona em uma maior predisposição para o sucesso escolar. Essas famílias tendem a valorizar a educação e condições financeiras para permitir que os filhos possam dedicar-se exclusivamente aos estudos por mais tempo. Segundo Dore e Luscher (2011) o nível educacional dos pais, a renda familiar, que no Brasil ainda está diretamente relacionada à escolaridade, e a estrutura da família são os fatores isolados mais importantes para o sucesso ou fracasso do estudante.

Tabela 1: Escolaridade do pai e da mãe dos participantes da pesquisa.

\begin{tabular}{l|l|l|l|l}
\hline & Escolaridade do pai & Evasão observada & Escolaridade da mãe & Evasão observada \\
\hline Não estudou & $2,8 \%$ & $33,3 \%$ & $1,9 \%$ & $50,0 \%$ \\
\hline Ensino fundamental incompleto & $20,8 \%$ & $18,2 \%$ & $18,9 \%$ & $35,0 \%$ \\
\hline Ensino fundamental completo & $7,5 \%$ & $37,5 \%$ & $3,8 \%$ & $25,0 \%$ \\
\hline Ensino médio incompleto & $5,7 \%$ & $16,7 \%$ & $6,6 \%$ & $14,3 \%$ \\
\hline Ensino médio completo & $25,5 \%$ & $25,9 \%$ & $26,4 \%$ & $21,4 \%$ \\
\hline Curso técnico & $9,4 \%$ & $50,0 \%$ & $11,3 \%$ & $25,0 \%$ \\
\hline Graduação incompleta & $5,7 \%$ & $0 \%$ & $3,8 \%$ & $25,0 \%$ \\
\hline Graduação completa & $17,9 \%$ & $31,6 \%$ & $26,4 \%$ & $32,1 \%$ \\
\hline Outro & $2,8 \%$ & $33,3 \%$ & $0 \%$ & $0 \%$ \\
\hline Prefiro não responder & $1,9 \%$ & $50 \%$ & $0,9 \%$ & $0 \%$ \\
\hline
\end{tabular}

Fonte: Dados da pesquisa.

Os estudantes também foram questionados a respeito do número de pessoas que residiam junto com eles. Esse resultado pode apontar para o quão tranqüilas são as condições que eles dispõem para estudar. As suas respostas apontam que $3,8 \%$ moram sozinhos, $18,9 \%$ moram com mais uma pessoa, $27,4 \%$ com mais duas, $30,2 \%$ com mais três, $10,4 \%$ com mais quatro e 9,4\% com mais de quatro. Quando calculada a média do número de habitantes por domicílio nesse grupo chega-se ao valor de 2,9, valor correspondente ao apresentado na Pesquisa Nacional por Amostras de Domicílios 2019 (PNAD) do IBGE que apontam para uma diminuição do tamanho da família brasileira ao longo dos anos.

Em seguida, foram perguntados se eles ou alguém que reside com eles foi diagnosticado com COVID-19. Foi 
observada uma taxa alta nesse grupo, já que 12,2\% receberam o diagnostico positivo e 4,7\% tiveram pessoas que moram junto contaminadas.

Apesar de ser consenso que o ensino remoto não pode ser considerado Educação a Distância, destacando-se que esse último possui legislação e características próprias, além de ser mais estruturado e complexo (Costa, 2020, Grossi, 2020), há algumas características em comum. Costa (2020) aponta a educação mediada por tecnologia e a ausência da coexistência de professores e alunos em um mesmo espaço físico, migrando as interações para Ambientes Virtuais de Aprendizagem e/ou ferramentas de webconferência. Nesse sentido, é provável que estudantes que já fizeram cursos a distância, possam ter maior familiaridade e maior adaptabilidade com as atividades remotas. Sendo assim, eles também foram perguntados se haviam feito cursos a distância no passado. As respostas indicam que 67\% não possuíam qualquer experiência pregressa, 17,9\% já haviam começado mas não haviam concluído e $15,1 \%$ haviam concluído o curso iniciado.

\subsection{Condições de estudo nas APNP}

Inicialmente, os alunos foram solicitados a comparar o aprendizado que eles estão tendo nesse período com o que apresentavam nos ensino regular presencial. Nas respostas foi utilizada a escala de Likert. Com relação àqueles que estão considerando o aprendizado superior ao presencial, apenas $0,9 \%$ considerou que está aprendendo muito mais do que no presencial e 5,7\% estão aprendendo mais. Os que consideram que o aprendizado está ocorrendo da mesma forma correspondem a $27,4 \%$ do grupo estudado. Quanto aos que estão aprendendo de forma inferior às atividades regulares presenciais, $24,5 \%$ avaliam que estão aprendendo menos e 32,1\% ponderam que estão aprendendo muito menos. A diferença para $100 \%$ corresponde àqueles que não souberam avaliar $(9,4 \%)$. Essa percepção de que estão aprendendo menos tem sido comum a grupos de estudantes diversos, como os do ensino fundamental (Grossi et al, 2020) além de estar presente em entrevistas com docentes (Fundação Carlos Chagas, 2020). Quando esse fator é relacionado ao abandono de disciplinas, observa-se que entre os estudantes que consideram que estão aprendendo igual ou de forma superior ao presencial, 19,4\% evadiram de alguma disciplina enquanto aqueles que consideram que seu aprendizado está ocorrendo de forma inferior foi de 31,7\%. Essa sensação pode ocasionar uma diminuição da motivação e levá-los a abandonar disciplinas.

$\mathrm{O}$ acesso a dispositivos para estudar pode ser determinante para o sucesso nesse período. Esse questionamento foi feito a eles considerando-se os dispositivos mais comuns disponíveis e também como era seu acesso, de uso exclusivo ou compartilhado. As respostas são apresentadas na Tabela 2.

Tabela 2: Acesso a dispositivos para estudo.

\begin{tabular}{l|l|l|l|l}
\hline & PC & Notebook & Celular & Tablet \\
\hline Não possuo & $71,7 \%$ & $23,6 \%$ & $4,7 \%$ & $91,5 \%$ \\
\hline Uso exclusivo & $8,5 \%$ & $34,9 \%$ & $90,6 \%$ & $5,7 \%$ \\
\hline Uso compartilhado & $19,8 \%$ & $41,5 \%$ & $4,7 \%$ & $2,8 \%$ \\
\hline
\end{tabular}

Fonte: Dados da pesquisa.

O IFFluminense lançou em agosto de 2020 programas de inclusão digital para estudantes com matrículas ativas. Até o dia 5 de janeiro de 2021, foram distribuídos 1400 tablets, 1885 chips para acesso à internet além de 135 auxílios para estudantes que residem em locais onde os chips não funcionam para adquirirem serviços de acesso à internet. (Fassarella, 2021). Com relação ao programa de acesso ofertado pela instituição, 10,4\% solicitaram o chip e foram contemplados, não obstante $4,7 \%$ não foram contemplados.

A rotina de estudos é um fator decisivo para aqueles que realizam estudos a distância. Nessa pergunta, eles foram questionados quantas horas por semana estavam dedicando a esse processo. Nas respostas, observa-se que 16\% não possuem 
rotina de estudos, 4,7\% dedicam-se menos de uma hora por semana, 19,8\% dedicam até 3 horas, 17,9\% até 5 horas e 41,5\% mais de 5 horas.

Na definição das características do ambiente de estudo, eles podiam selecionar quantas opções desejassem, sendo assim a soma das respostas não totaliza 100\%. Nota-se que, apenas 34\% possuem um espaço de uso exclusivo para estudarem, $38,7 \%$ compartilham esse espaço com outras pessoas e $29,2 \%$ não possuem um ambiente dedicado a essa finalidade. No tocante ao mobiliário que dispõem, 64,2\% possuem mesa e 61,3\% possuem cadeira. Com relação às qualidades que contribuem no processo de aprendizagem, 38,7\% classificam-no seu ambiente como tranqüilo, 42,5\% como arejado, 51,9\% como bem iluminado e 42,5\% como organizado. Ou seja, para os demais estudantes o ambiente é barulhento (44,3\%), quente $(20,8 \%)$, escuro $(7,5 \%)$ e desorganizado $(21,7 \%)$.

Com referência aos sentimentos negativos que vêm experimentando nesse período, os estudantes também podiam assinalar quantas respostas desejassem e o relato mostra tristeza $(37,7 \%)$, ansiedade $(72,6 \%)$, insegurança $(57,5 \%)$, estresse $(60,4 \%)$, desânimo (67\%), medo (27,4\%), angústia (38,7\%), solidão (16,0\%), incapacidade (45,3\%), falta de motivação $(67,9 \%)$, preocupação $(70,8 \%)$, confuso $(46,2 \%)$, raiva $(23,6 \%)$ e cansaço $(60,4 \%)$.

Maia e Dias (2020) realizaram um estudo comparativo entre estudantes universitários em Portugal considerando um período anterior à pandemia e o período de atividades remotas. Os autores observaram que os estudantes durante a pandemia apresentaram níveis de ansiedade, estresse e depressão significativamente superiores aos que apresentavam durante as atividades presenciais que já é alto. Os autores comentam ainda que um amplo estudo de revisão permitiu perceber que após períodos de quarentena os indivíduos podem apresentar efeitos psicológicos negativos como raiva, confusão e até estresse póstraumático. As instituições deverão estar atentas a esse quadro e conforme alertam esses autores.

Num momento posterior, certamente será necessário "aprofundar a discussão e criar programas de promoção de competências sociais e emocionais junto de populações mais jovens, bem como estratégias de remediação para episódios" (Maia \& Dias, 2020, p.7)

Além disso, esses sentimentos podem afetar de forma significativa o aprendizado dos estudantes (Santos, 2007) e, aliado às dificuldades de terem que se adequar a essa oferta de aulas, pode levá-los a de fato aprenderem menos, como é a percepção de muitos deles, como evidenciado anteriormente.

Os resultados da análise dos estudantes quanto à saúde mental também são impactantes, pois na escala de Likert $20,8 \%$ responderam que piorou muito e $38,7 \%$ piorou. $26,4 \%$ analisam que não foi afetada e $11,3 \%$ acham que melhorou e 2,8\% que melhorou muito. Quando é aplicado um filtro de gênero, observa-se que as mulheres estão sentindo mais os efeitos na saúde mental já que $24,6 \%$ alegam ter piorado muito e $40 \%$ que piorou. Esses dados corroboram os encontrados em um estudo realizado com estudantes chineses que mostrou que as mulheres têm apresentado quadros de estresse, ansiedade e depressão mais severos que os homens durante as atividades remotas, essa discrepância não é facilmente observada em outras situações (Wang et al, 2020). No Brasil, Bartmeyer e Salles Filho (2020) observaram que os homens tiveram sua saúde mental menos afetada que as mulheres e questionam se isso pode estar relacionado à maior dificuldade que os homens têm em admitir isso e falar abertamente sobre seus sentimentos.

\subsection{Compreendendo os efeitos que levam os estudantes a abandonar disciplinas}

Diante desses sentimentos adversos e condições pouco adequadas de estudo apontada por eles, o índice de evasão das disciplinas tem sido elevado. Com relação ao público que participou da pesquisa, observa-se uma evasão de 27,3\%, sendo que $30,7 \%$ das mulheres e $21,9 \%$ do total de homens matriculados. A Tabela 3 mostra a evasão por número de disciplinas e gênero e se possuem filhos. Os dados corroboram como as mulheres representam a maior porcentagem do público evadido, com exceção da evasão em todas as disciplinas no qual é igual. Como foi mostrado anteriormente, esse público é o mais afetado por 
questões psicológicas como depressão, estresse e ansiedade o que pode contribuir para esses resultados observados. No que se refere ao número de filhos que também poderia ocasionar uma sobrecarga nos pais e mães estudantes, a maioria (83\%) não possui, enquanto que 7,5\% possui um, 6,6\% possui dois e 2,8\% possui três. Quando se faz a relação entre possuir filhos e o abandono de disciplinas não fica evidente que esse fator pode contribuir para a decisão dos estudantes.

Tabela 3: Evasão de disciplinas durante as APNP relacionadas ao gênero e número de filhos.

\begin{tabular}{l|l|l|l|l|l}
\hline $\begin{array}{l}\text { Número de disciplinas } \\
\text { abandonadas }\end{array}$ & Geral & Feminino & Masculino & \multicolumn{2}{|l}{ Possui filhos? } \\
\cline { 5 - 6 } & & & & Sim & Não \\
\hline 0 & $72,6 \%$ & $58,4 \%$ & $41,6 \%$ & $72,2 \%$ & $72,7 \%$ \\
\hline 1 & $10,4 \%$ & $54,5 \%$ & $45,5 \%$ & $16,7 \%$ & $9,1 \%$ \\
\hline 2 & $5,7 \%$ & $100 \%$ & 0 & $0,0 \%$ & $6,8 \%$ \\
\hline 3 & $3,8 \%$ & $100 \%$ & 0 & $5,6 \%$ & $3,4 \%$ \\
\hline 4 & $2,8 \%$ & $100 \%$ & 0 & $5,6 \%$ & $2,3 \%$ \\
\hline 5 & $1,9 \%$ & $100 \%$ & 0 & $0,0 \%$ & $2,3 \%$ \\
\hline Mais de 5 & $0,9 \%$ & $100 \%$ & 0 & $0,0 \%$ & $1,1 \%$ \\
\hline Todas & $1,9 \%$ & $50 \%$ & $50 \%$ & $0,0 \%$ & $2,3 \%$ \\
\hline
\end{tabular}

Fonte: Dados da pesquisa.

Quando selecionavam que haviam abandonado alguma disciplina eles eram direcionados a perguntas para melhor compreensão dessa decisão. Dentro desse grupo, 37,9\% já haviam abandonado disciplina(s) em outro momento do curso. As principais causas relacionadas à instituição que levaram esses estudantes a abandonar foram dificuldades com o MOODLE (20,7\%), dificuldades com os conteúdos $(31 \%)$, com a forma como a disciplina estava sendo ofertada $(55,2 \%)$ e excesso de conteúdo $(41,4 \%)$. As principais razões não relacionadas à instituição foram, falta de tempo e/ou dificuldade de conciliar com outras atividades $(62,1 \%)$, não adaptação às atividades remotas (48,3\%), fatores de ordem emocional/psicológica $(48,3 \%)$ e falta de motivação $(62,1 \%)$. Apesar de terem sido selecionados por um menor número de estudantes, merecem destaque ainda dificuldades com acesso à internet (17,2\%), problemas de saúde (27,6\%), dificuldades financeiras (27,6\%), falta de determinação (31\%) e matriculou-se em um número excessivo de disciplinas (27,6\%).

$\mathrm{Na}$ ausência de estudos que tratem da evasão durante a pandemia, parece mais adequado utilizar referenciais de evasão da $\mathrm{EaD}$ do que do ensino presencial. Nesse sentido, é muito comum que os estudantes apontem a falta de tempo como principal razão, quando na verdade pode haver outras razões por trás como falta de motivação ou dificuldades com as disciplinas (Grote, 2000 como citado em Laguardia \& Portela, 2009), falta de disposição para reservar parte do seu tempo para o estudo (Bourdages, 1996 como citado em Laguardia \& Portela, 2009), falta de rotina de estudos (Nunes \& Oliveira, 2018), sobrecarga de atividades ou excesso de novos conceitos ou mesmo quando querem se esquivar de falar das verdadeiras razões (Simpson, 2010a, 2010b).

Sendo assim, para compreender melhor se a razão falta de tempo pode ter outros fatores por trás, foram estabelecidas correlações entre a evasão de disciplinas e outras respostas indicadas por eles.

A Tabela 4 apresenta os dados de evasão relacionados aos grupos que estão envolvidos com trabalho, outros cursos e tarefas domésticas. Quando foram relacionadas o número de disciplinas evadidas com a situação envolvendo o trabalho, observa-se que a porcentagem de estudantes que não evadiu de nenhuma disciplina é maior entre aqueles que não estavam trabalhando o que pode significar que os que trabalham tem uma maior propensão a abandonar algum componente. No entanto, não há essa mesma correlação quando estão fazendo outros cursos. Quando esses dados são refinados, analisando-se com a natureza do curso que os estudantes estão fazendo a maior taxa (37,5\%) é observada entre aqueles que estão fazendo o curso técnico simultaneamente. É muito comum no instituto que os estudantes do ensino superior façam um curso técnico para garantir a gratuidade no transporte público que não é concedido para estudantes universitários. 
Com relação às tarefas domésticas, consideraram-se dois grupos distintos no primeiro foram agrupados aqueles que sinalizaram que dividem igualmente, realizam a maior parte ou é responsável por todas e no segundo grupo aqueles que fazem poucas ou nenhuma. Nessa situação, observa-se também que a taxa de retenção foi maior entre aqueles que não fazem muitas tarefas em casa.

Tabela 4: Relação entre atividades extras desenvolvidas pelos estudantes e evasão das disciplinas.

\begin{tabular}{|c|c|c|c|c|c|c|}
\hline & \multicolumn{2}{|c|}{ Trabalhando? } & \multicolumn{2}{|c|}{$\begin{array}{ll}\text { Fazendo } & \text { outros } \\
\text { cursos? } & \\
\end{array}$} & \multicolumn{2}{|c|}{$\begin{array}{l}\text { Realiza todas ou a maior parte das tarefas } \\
\text { domésticas? }\end{array}$} \\
\hline $\begin{array}{l}\text { Número de disciplinas abandonadas } \\
\text { durante APNP }\end{array}$ & Sim & Não & Sim & Não & Sim & Não \\
\hline 0 & $28,3 \%$ & $44,3 \%$ & $40,6 \%$ & $32,1 \%$ & $71,4 \%$ & $80,0 \%$ \\
\hline 1 & $4,7 \%$ & $5,7 \%$ & $6,6 \%$ & $3,8 \%$ & $11,0 \%$ & $6,7 \%$ \\
\hline 2 & $4,7 \%$ & $0,9 \%$ & $1,9 \%$ & $3,8 \%$ & $5,5 \%$ & $6,7 \%$ \\
\hline 3 & $3,8 \%$ & $0,0 \%$ & $0,0 \%$ & $3,8 \%$ & $4,4 \%$ & $0,0 \%$ \\
\hline 4 & $0,9 \%$ & $1,9 \%$ & $0,9 \%$ & $1,9 \%$ & $3,3 \%$ & $0,0 \%$ \\
\hline 5 & $0,0 \%$ & $1,9 \%$ & $0,9 \%$ & $0,9 \%$ & $1,1 \%$ & $6,7 \%$ \\
\hline Mais de 5 & $0,0 \%$ & $0,9 \%$ & $0,9 \%$ & $0,0 \%$ & $1,1 \%$ & $0,0 \%$ \\
\hline Todas & $0,9 \%$ & $0,9 \%$ & $0,9 \%$ & $0,9 \%$ & $2,2 \%$ & $0,0 \%$ \\
\hline
\end{tabular}

Fonte: Dados da pesquisa

Quando foi analisada se há correlação nos hábitos de estudo com a evasão, observou-se que as maiores taxas encontraram-se entre aqueles que estudam menos de 1 hora por semana (60\%). Nessas situações, muitas vezes as atividades e conteúdos acumulam-se e a sensação de que não dará conta pode levar o estudante a abandonar a disciplina. Esse resultado apóia o que foi exposto anteriormente que a falta de tempo pode também estar relacionada a outros fatores, além do trabalho e participação em tarefas domésticas.

Os estudantes que selecionaram que abandonaram todas as disciplinas responderam a uma pergunta adicional sobre a sua intenção de retomar os estudos e todos apontaram que só o farão quando as atividades voltarem a ser presenciais. Isso indica que, até o presente momento, não há evasão total dos cursos analisados.

\section{Conclusão}

O mundo está passando por situações sem precedentes ocasionadas pela pandemia causada pelo COVID-19. Decretos determinaram o fechamento de estabelecimentos comerciais e também de instituições educacionais. A inserção das tecnologias nas escolas vinha ocorrendo de forma lenta e, por causa da impossibilidade da manutenção das formas tradicionais, precisou ser acelerada para que a oferta de educação pudesse ser mantida de forma segura. Os docentes precisaram investir em equipamentos e aprender rapidamente a utilizar as tecnologias que tinham à disposição para manterem as atividades em home office.

Esse processo aumentou ainda mais as desigualdades vividas pela educação visto que as instituições privadas conseguiram dar uma resposta muito mais rápida à crise, até mesmo para manter sua saúde financeira. As instituições públicas necessitaram de mais tempo e como muitas vezes atendem estudantes em vulnerabilidade social, muitos desses não têm acesso aos dispositivos adequados ou à internet de qualidade suficiente. Há uma enorme preocupação de que a evasão, que já era alta no Brasil, e que já experimentou um aumento na pandemia, siga ainda maior, mesmo após a reabertura das escolas. A evasão é um fenômeno complexo, multifacetado e causado por variáveis diversas, apesar das dificuldades intrínsecas em estudá-lo, é fundamental compreender as causas para que medidas sejam tomadas.

Nesse estudo observou-se que os maiores evadidos são as mulheres e também aqueles que possuem pais e mães pouco 
escolarizados. No que tange às causas, o acúmulo de tarefas e a falta de uma rotina de estudos destacam-se.

Nesta pesquisa foi possível verificar que mesmo aqueles estudantes que não evadiram de nenhuma disciplina, relatam sentimentos como ansiedade, falta de motivação, cansaço e estresse, entre outros sentimentos negativos. Esses sentimentos aliados à rápida adaptação, ou pelo menos tentativa, podem levá-los a experimentar a sensação de que estão aprendendo menos. Huang et al (2020) aponta que será um desafio medir e validar o que se aprendeu no ensino remoto. Além disso, as instituições terão que estar preparadas para dar suporte psicológico e pedagógico a esses estudantes.

\section{Agradecimentos}

À Susany Sales Brandão e Maira Freitas Cardoso pelas informações dos estudantes, aos coordenadores de curso pela ajuda na divulgação entre os estudantes.

In memorian de Carlos Fabiano de Souza.

\section{Referências}

Alon, T. M., Doepke, M., Olmstead-Rumsey, J., \& Tertilt, M. (2020). The impact of COVID-19 on gender equality . National Bureau of economic research. https://doi.org/10.3386/w26947

Arntz, M., Yahmed, S. B. \& Berlingieri, F. (2020). Working from Home and COVID-19: The Chances and Risks for Gender Gaps. Intereconomics, 55(6), 381-386. $10.1007 / \mathrm{s} 10272-020-0938-5$

Barbosa, A. M., Viegas, M. A. S., \& Batista, R. L. N. F. F. (2020). Aulas presenciais em tempos de pandemia: relatos de experiências de professores do nível superior sobre as aulas remotas. Revista Augustus, 25(51), 255-280. https://doi.org/10.15202/1981896.2020v25n51p255

Bartmeyer, S. M., \& Salles Filho, N. A. (2020). O direito humano das mulheres à educação e a pandemia da COVID-19: uma análise da sobrecarga das estudantes da UEPG. Revista Científica Educ@ção, 4(8), 1043-1060. https://doi.org/10.46616/rce.v4i8.106

Carneiro, L. D. A., Rodrigues, W., França, G., \& Prata, D. N. (2020). Use of technologies in Brazilian public higher education in times of pandemic COVID19. Research, Society and Development, 9(8). https://doi.org/10.33448/rsd-v9i8.5485

Chyung, Y. (2001). Systemic and systematic approaches to reducing attrition rates in online higher education. The American Journal of Distance Education, 15(3), 36-49. https://doi.org/10.1080/08923640109527092

Costa, R. (2020). Educação remota emergencial x EaD: desafios e oportunidades. https://www.linkedin.com/pulse/educa\%C3\%A7\%C3\%A3o-remotaemergencial-x-ead-desafios-e-renata-costa

Couto, E. S., Couto, E. S., \& Cruz, I. D. M. P. (2020). \# Fiqueemcasa: educação na pandemia da COVID-19. Interfaces Científicas-Educação, 8(3), 200-217. https://doi.org/10.17564/2316-3828.2020v8n3p200-217

Decreto $\mathrm{n}^{\circ}$ 9.057, de 25 de maio de 2017 (2017, 26 maio). Regulamenta o art. 80 da Lei $\mathrm{n}^{\circ}$ 9.394, de 20 de dezembro de 1996 , que estabelece as dire trizes e bases da educação nacional. Diário Oficial da União, ed. 100, seção 1, Brasília, DF, 3, 26 mai. 2017. http://www.planalto.gov.br/ccivil_03/_ato20152018/2017/decreto/d9057.htm

Dore, R. \& Lüscher, A. Z. (2011). Permanência e evasão na educação técnica de nível médio em Minas Gerais. Cadernos de pesquisa, 41(144), 770-789. http://dx.doi.org/10.1590/S0100-15742011000300007

Fassarella, A. P. G. (2021) IFF disponibiliza mais de 1.400 tablets para estudantes por meio do Auxílio Inclusão Digital. Instituto Federal de Educação, Ciência e Tecnologia Fluminense. http://portal1.iff.edu.br/reitoria/noticias/iff-disponibiliza-mais-de-1-400-tablets-para-estudantes-por-meio-do-auxilioinclusao-digital

Fritsch, R., da Rocha, C. S., \& Vitelli, R. F. (2015). A evasão nos cursos de graduação em uma instituição de ensino superior privada. Revista Educação em Questão, 52(38), 81-108. https://doi.org/10.21680/1981-1802.2015v52n38ID7963

Fundação Carlos Chagas (FCC). (2020) Educação escolar em tempos de pandemia. https://www.fcc.org.br/fcc/educacao-pesquisa/educacao-escolar-emtempos-de-pandemia-informe-n-1

Gil, A. C. (2002). Como elaborar projetos de pesquisa. Editora Atlas S.A.

Grossi, M. G. R. (2020) O ensino remoto é uma modalidade de educação? https://avacefetmg.org.br/.

Grossi, M. G. R., Minoda, D. D. S. M. \& Fonseca, R. G. P. (2020). Impacto da pandemia do COVID-19 na educação: reflexos na vida das famílias. Teoria e Prática da Educação, 23(3), 150-170. https://doi.org/10.4025/tpe.v23i3.53672

Grubic, N., Badovinac, S., \& Johri, A. M. (2020). Student mental health in the midst of the COVID-19 pandemic: A call for further research and immediate solutions. International Journal of Social Psychiatry, 66(5), 517-518. https://doi.org/10.1177/0020764020925108 
Gusso, H. L., Archer, A. B., Luiz, F. B., Sahão, F. T., Luca, G. G. D., Henklain, M. H. O., \& Gonçalves, V. M. (2020). Ensino superior em tempos de pandemia: diretrizes à gestão universitária. Educação \& Sociedade, 41. https://doi.org/10.1590/es.238957

Hodges, C., Moore, S., Lockee, B., Trust, T. \& Bond, A. (2020). The difference between emergency remote teaching and online learning. Educause review, 27, 1-12. https:// er.educause.edu/articles/2020/3/the-difference-between-emergency-remote-teaching-and-online-learning

Huang, R. H., Liu, D. J., Tlili, A., Yang, J. F., \& Wang, H. H. (2020). The Chinese experience in maintaining undisrupted learning in COVID-19 outbreak. Handbook on Facilitating Flexible Learning During Educational Disruption. https://iite.unesco.org/wpcontent/uploads/2020/03/Handbook-onFacilitating-Flexible-Learning-in-COVID-19-Outbreak-SLIBNU-V1.2-20200315.pdf.

Instituto Brasileiro de Geografia e Estatística (IBGE) (2019). Pesquisa traz dados referentes à divisão de tarefas domésticas. https://www.cnm.org.br/comunicacao/ noticias/pesquisa-traz-dados-referentes-a-divisao-de-tarefas-domesticas

Instituto Brasileiro de Geografia e Estatística (IBGE). (2019). Pesquisa nacional por amostra de domicílios (PNAD). https://biblioteca.ibge.gov.br/visualizacao/livros/liv101707_informativo.pdf

Kember, D. (1989). A longitudinal-process model of drop-out from distance education. The Journal of Higher Education, 60(3), 278-301. https://doi.org/10.1080/00221546.1989.11775036

Laguardia, J., \& Portela, M. (2009). Evasão na educação a distância. ETD-Educação Temática Digital, 11(1), 349-379. https://doi.org/10.20396/etd.v11i1.929

Lemos, A. H. D. C., Barbosa, A. D. O., \& Monzato, P. P. (2020). Women in home office during the COVID-19 pandemic and the work-family conflict configurations. Revista de Administração de Empresas, 60(6), 388-400. http://dx.doi.org/10.1590/S0034-759020200603

Levy, Y. (2007). Comparing dropouts and persistence in e-learning courses. Computers \& Education, 48, 185-204. https://doi.org/10.1016/j.compedu.2004.12.004

Maia, B. R., \& Dias, P. C. (2020). Ansiedade, depressão e estresse em estudantes universitários: o impacto da COVID-19. Estudos de Psicologia (Campinas), 37. 1-8. https://doi.org/10.1590/1982-0275202037e200067

Meeter, M., Bele, T., den Hartogh, C., Bakker, T., de Vries, R. E., \& Plak, S. (2020). College students' motivation and study results after COVID-19 stay-athome orders. PsyArxiv. https://doi.org/10.31234/osf.io/kn6v9

Núcleo da Informação e Coordenação do Ponto BR - NIC.br (2019). Pesquisa sobre o uso das tecnologias de informação e comunicação: pesquisa TIC Domicílios, ano 2019.https://cetic.br/media/analises/tic_domicilios_2019_coletiva_imprensa.pdf

Nunes, R. C., \&Oliveira, T. S. A. (2018) Análise da evasão em cursos técnicos a distância a partir do perfil e da percepção dos estudantes In: GROSSI, M.G.R. (org) Tecnologias digitais: desafios, possibilidades e relatos de experiências (p. 57-80). Brasília, Ibict.

Ordem de Serviço n 33 de 22 de setembro de 2020 (2020). Autoriza a oferta de Atividades Pedagógicas Não Presenciais (APNP) no âmbito do Campus Cabo Frio, no período de 21 de setembro de 2020 a 12 de março de 2021 , conforme plano aprovado pelo Conselho de Campus, em reunião realizada em 17 de setembro de 2020. http://cdd.iff.edu.br/documentos/ordens-de-servico/cabo-frio/2020/setembro/ordem_de_servico-1/view/++widget+ +form.widgets.arquivo/@@download/OS+33.pdf.

Organização das Nações Unidas para a Educação, a Ciência e a Cultura (UNESCO) (2020). COVID-19: como a Coalizão Global de Educação da UNESCO está lidando com a maior interrupção da aprendizagem da história. https://pt.unesco.org/news/covid-19-como-coalizao-global-educacao-da-unesco-estalidando-com-maior-interrupcao-da

Paranhos, R., Figueiredo Filho, D. B., da Rocha, E. C., \& da Silva Junior, J. A. (2013). Corra que o survey vem aí. Noções básicas para cientistas sociais. Revista Latinoamericana de Metodología de la Investigación Social, 6, 7-24. http://www.relmis.com.ar/ojs/index.php/relmis/article/view/74

Park, J-H., \& CHOI, H. J. (2009). Factors Influencing Adult Learners' Decision to Drop Out or Persist in Online Learning. Educational Technology \& Society, 12(4), 207-217. https://www.jstor.org/stable/pdf/jeductechsoci.12.4.207.pdf?_=1459005475270

Pereira, A. S., Shitsuka, D. M., Parreira, F. J., \& Shitsuka, R. (2018). Metodologia da Pesquisa Científica. Santa Maria, UFSM.

Portaria no 343, de 17 de março de 2020 (2020, 18 março). Dispõe sobre a substituição de aulas presenciais por aulas em meios digitais en quanto durar a situação de pandemia do Novo Coronavírus - COVID-19. Diário Oficial da União, ed. 53, seção 1, Brasília, DF, p. 39 , 18 mar. 2020. https://www.in.gov.br/en/web/dou/-/portaria-n-343-de-17-de-marco-de-2020-248564376

Portaria no 345, de 19 de março de 2020 (2020, 19 março). Altera a Portaria MEC n 343, de 17 de março de 2020. Diário Oficial da União, ed. 54, seção 1 , Brasília, DF, p. 1, 18 mar. 2020. https://www.in.gov.br/en/web/dou/-/portaria-n-343-de-17-de-marco-de-2020-248564376

Portaria $\mathrm{n}^{\circ} 577$ de 31 de agosto de 2020 (2020, 31 agosto). Dispõe sobre a reabertura dos calendários dos campi do IFFluminense. http://cdd.iff.edu.br/documentos/portarias/reitoria/gabinete/2020/agosto/portaria-67/view/++widget++form.widgets.arquivo/@@download/Portaria+N.\% C2\%BA+ 577\%2C+de+31+de+agosto+de+2020.pdf.

Saldaña, P. (2021) Cerca de 4 milhões abandonaram a estudos na pandemia, diz estudo. Folha de São Paulo. https://www1.folha.uol.com.br/educacao/2021/01/cerca-de-4-milhoes-abandonaram-estudos-na-pandemia-diz-pesquisa.shtml

Santos, F. M. T. D. (2007). As emoções nas interações e a aprendizagem significativa. Ensaio Pesquisa em Educação em Ciências (Belo Horizonte), 9(2), 173187. https://doi.org/10.1590/1983-21172007090202

Silva, R. M. A., Oliveira, T. S. A., \$ Nunes, R. C. (2016). Análise do perfil sócio-demográfico de alunos evadidos e não evadidos em cursos técnicos a distância. XIII Congresso Brasileiro de Ensino Superior a Distância (p. 784-797), São João Del Rey. 
Research, Society and Development, v. 10, n. 3, e1410313022, 2021

(CC BY 4.0) | ISSN 2525-3409 | DOI: http://dx.doi.org/10.33448/rsd-v10i3.13022

Simpson, O. (2010a). Course design and student retention. www.ormondsimpson.com.

Simpson, O. (2010b). $22 \%$ - can we do better? www.ormondsimpson.com.

Tinto, V. (1998). Colleges as Communities: Taking Research on Student Persistence Seriously. The Review of Higher Education 21(2), 167177. https://www.muse.jhu.edu/article/30046

Trolian, T. L., Jach, E. A., Hanson, J. M., \& Pascarella, E. T. (2016). Influencing Academic Motivation: The Effects of Student-Faculty Interaction. Journal of College Student Development, 57, 810-826. 10.1353/csd.2016.0080

Wang, C., Pan, R., Wan, X., Tan, Y., Xu, L., Ho, C. S., \& Ho, R. C. (2020). Immediate psychological responses and associated factors during the initial stage of the 2019 coronavirus disease (COVID-19) epidemic among the general population in China. International journal of environmental research and public health, 17(5), 1729. https://doi.org/10.3390/ijerph17051729 